\title{
Sequential Treatment of Landfill Leachate By Advanced Oxidation Processes and Struvite Precipitation
}

\section{Sushma lavudya}

JNTUH IST: Jawaharlal Nehru Technological University Hyderabad Institute of Science \& Technology maneesha vodnala

JNTUH IST: Jawaharlal Nehru Technological University Hyderabad Institute of Science \& Technology

Bhagawan Dheeravath

JNTUH IST: Jawaharlal Nehru Technological University Hyderabad Institute of Science \& Technology

kiran kumar Panga

JNTUH IST: Jawaharlal Nehru Technological University Hyderabad Institute of Science \& Technology

Vijaya krishna saranga

JNTUH IST: Jawaharlal Nehru Technological University Hyderabad Institute of Science \& Technology

Shankaraiah Golla

JNTUH IST: Jawaharlal Nehru Technological University Hyderabad Institute of Science \& Technology

Himabindu V ( $\nabla$ drvhimabindu@jntuh.ac.in )

JNTUH IST: Jawaharlal Nehru Technological University Hyderabad Institute of Science \& Technology

\section{Srinath Suranani}

NIT Warangal: National Institute of Technology Warangal

\section{Research}

Keywords: Chemical Oxygen Demand, Electrooxidation, Fenton, Landfill leachate, and Struvite

Posted Date: July 7th, 2021

DOI: https://doi.org/10.21203/rs.3.rs-627238/v1

License: (1) (1) This work is licensed under a Creative Commons Attribution 4.0 International License.

Read Full License 
1 Sequential treatment of Landfill Leachate by Advanced Oxidation Processes (AOP's)

2

3

4

\section{and Struvite Precipitation}

Sushma Lavudya ${ }^{1}$, Maneesha Vodnala ${ }^{1}$, Bhagawan Dheeravath ${ }^{1}$, Kirankumar Panga $^{1}$,

Saranga Vijaya Krishna ${ }^{1}$, Shankaraiah Golla ${ }^{1}$, Vurimindi Himabindu ${ }^{1 *}$, Srinath Suranani ${ }^{2}$

1. Centre for Environment, Institute of Science and Technology, JNTUH, Hyderabad, India-500085

2. Department of Chemical Engineering, National Institute of Technology, Warangal, India- 506004

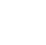

4 Corresponding Author:

Dr. V. HIMABINDU, Ph.D.,

\section{PROFESSOR}

Centre for Environment

Coordinator for Centre for Alternative Energy Options

Institute of Science and Technology

JAWAHARLAL NEHRU TECHNOLOGICAL UNIVERSITY HYDERABAD,

21 Kukatpally, Hyderabad 500085, TELANGANA, INDIA

22 Email: drvhimabindu@jntuh.ac.in 


\section{Abstract:}

Landfill leachate contains organic, inorganic compounds, heavy metals, ammonia, and xenobiotic compounds which are considered unsafe for discharging into surface water which requires to be treated before its discharge into the water. In this paper, preliminary studies are reported on the application of Fenton, Struvite, and Electrooxidation processes for the removal of Chemical Oxygen Demand (COD) and ammonia from landfill leachate. Various operational parameters like $\mathrm{pH}$, dosage, reaction time, and applied voltage were optimized in laboratory batch experiments and evaluated for removal of COD and ammonia. Results demonstrated that the Fenton process could effectively remove COD and ammonia by $75 \%$ and $23 \%$ respectively at 210 min for $\mathrm{Fe}^{+2}: \mathrm{H}_{2} \mathrm{O}_{2}: 1: 5$ at a fixed $\mathrm{pH}$ 3. The Struvite process has been effective in the removal of ammonia by $74 \%$ at $\mathrm{pH} 9$ with the dosage of $\mathrm{Mg}^{+2}: \mathrm{PO}_{4}{ }^{3-}: \mathrm{NH}^{4+}$ at $1: 1: 1$ ratio. Results from Electrooxidation for COD and ammonia were observed as $58.25 \%$ and $44 \%$ respectively at the applied voltage $8 \mathrm{~V}$ for a reaction time of $60 \mathrm{~min}$. The efficiency of treatment processes was also evaluated in Sequential processes for COD and ammonia i.e., Sequence-I (FentonElectrooxidation-Struvite) and Sequence-II (Fenton-Struvite) at pre-optimized conditions. The sequential processes have been depicted, the removal efficiencies of COD and ammonia of $89 \%$ and $82 \%$ by Sequence-I; $76.77 \%$, and $77 \%$ by Sequence-II respectively. The present study demonstrates that Fenton followed by Electrooxidation and Struvite is an effective treatment process that can enhance the treatment of landfill leachate.

Keywords: Chemical Oxygen Demand, Electrooxidation, Fenton, Landfill leachate, and Struvite 


\section{Introduction}

Management of Landfill Leachate is a serious problem that contains organic and inorganic compounds, heavy metals, high ammonia content, and xenobiotic compounds. The physical and chemical characteristics of landfill leachate vary significantly with time, age of landfill, engineering aspects of the landfill and characteristics of dumped waste [1]. Depending on the characteristics, leachate is classified into legacy (old) landfill leachate and new landfill leachate. To prevent environmental impacts from landfill leachate, it is necessary to treat it before its discharge into the aquatic environment. With the diversified characteristics of landfill leachate, conventional treatment methods may not be feasible in the treatment of landfill leachate. Several techniques implemented for the treatment of landfill leachate were adsorption methods, chemical precipitation, anaerobic and aerobic biological methods, and advanced oxidation processes (AOP). The above-mentioned treatment techniques have limitations like less sensitivity, scaling and less biodegradability [2]. AOP's have increased attention in recent times because of the oxidation potential of Hydroxyl radicals [ $\left.{ }^{\circ} \mathrm{OH}\right]$. AOP's were successfully applied for the treatment of a wide variety of low biodegradable organic compounds in industrial wastewaters as well as landfill leachate. In the treatment of landfill leachate, the organic compounds are converted into less toxic intermediates or completely get mineralized. AOP's entirely depends on the liberation of hydroxyl radicals in Fenton, PhotoFenton, ElectroFenton, Electrooxidation, Ozonation, and Photocatalytic oxidation. Along with AOP's, the Struvite precipitation process contributes to the enhancing of treatment efficiency of landfill leachate

Fenton reaction is one of the most successful and widely used AOP's and is based on the chemistry of hydroxyl radicals $\left[{ }^{\circ} \mathrm{OH}\right]$, which has the strongest oxidation potential when compared to ozone. The liberated $\left[{ }^{\circ} \mathrm{OH}\right]$ oxidizes the organic compounds and mineralizes them into either intermediate compounds or completely degraded products in presence of catalyst 
[3]. The reaction occurring in Fenton systems results in the formation of ferric hydroxo compounds depending on the ratio of $\mathrm{H}_{2} \mathrm{O}_{2}$ and $\mathrm{Fe}^{2+}$. Catalysts of Iron salts like $\mathrm{FeSO}_{4} .7 \mathrm{H}_{2} \mathrm{O}$ and $\mathrm{FeCl}_{3}$ can be used in the Fenton process have a synergistic effect on organic compounds when combined with Hydrogen peroxide $\left(\mathrm{H}_{2} \mathrm{O}_{2}\right)$ under strong acidic conditions as shown in Eqs (1) and (2) [4].

7

8

9

The net decomposition of $\mathrm{H}_{2} \mathrm{O}_{2}$ is as follows:

$$
\begin{array}{ll}
\mathrm{Fe}^{2+}+\mathrm{H}_{2} \mathrm{O}_{2} \rightarrow \mathrm{Fe}^{3+}+\left[{ }^{\circ} \mathrm{OH}\right]+\mathrm{OH}^{-} & \text {Eq. } 1 \\
\mathrm{Fe}^{3+}+\mathrm{H}_{2} \mathrm{O}_{2} \rightarrow \mathrm{Fe}^{2+}+\mathrm{HO}_{2}^{\cdot}+\mathrm{H}^{+} & \text {Eq. } 2
\end{array}
$$

$$
\mathrm{H}_{2} \mathrm{O}_{2} \rightarrow \mathrm{H}_{2} \mathrm{O}+\mathrm{O}_{2}
$$

Electrooxidation is a powerful technique used in treating landfill leachate. In Electrooxidation, direct current is applied to generate free radicals as in Eq. (4). The generated radicals display a substantial role in the complete degradation of organic compounds by mineralization along with carbon dioxide and water as expressed in Eq. (5) [5].

$$
\mathrm{H}_{2} \mathrm{O} \rightarrow\left[{ }^{\circ} \mathrm{OH}\right]+\mathrm{H}^{+}+\mathrm{e}^{-} \quad \text { Eq. } 4
$$$$
\left[{ }^{\circ} \mathrm{OH}\right]+\text { Organic Compounds } \rightarrow \text { oxidized compound }+\mathrm{CO}_{2}+\mathrm{H}_{2} \mathrm{O}+\mathrm{H}^{+}+\mathrm{e}^{-}
$$

Struvite precipitation is one of the most effective in the treatment of ammonia [6]. Various Magnesium and Phosphorus salts like $\mathrm{MgCl}_{2} .6 \mathrm{H}_{2} \mathrm{O}, \mathrm{Na}_{2} \mathrm{HPO}_{4} \cdot 12 \mathrm{H}_{2} \mathrm{O}, \mathrm{MgO}, \mathrm{H}_{3} \mathrm{PO}_{4}$, $\mathrm{Ca}\left(\mathrm{H}_{2} \mathrm{PO}_{4}\right)_{2} \cdot \mathrm{H}_{2} \mathrm{O}$ and $\mathrm{MgSO}_{4} \cdot 7 \mathrm{H}_{2} \mathrm{O}$, etc., are extensively used in precipitating ammonia Eq. (6) [7]. Struvite is insoluble which can be easily separated from water and can be used as fertilizer for plants that require magnesium for growth.

$$
\mathrm{Mg}^{+2}+\mathrm{PO}_{4}{ }^{3-}+\mathrm{NH}^{4+} \rightarrow \mathrm{MgNH}_{4} \mathrm{PO}_{4} \cdot 6 \mathrm{H}_{2} \mathrm{O}
$$

Eq. 6

Fenton, Electrooxidation, and Struvite process are entirely dependent on operating conditions and initial characteristics of landfill leachates. In the present study, the experiments 
were carried out for the removal of Chemical Oxygen Demand (COD) and ammonia from landfill leachate wastewater using Fenton, Struvite, and Electrooxidation processes. Different operational parameters like $\mathrm{pH}$, reaction time, dosage, inner Electrode distance and applied voltage were optimized. Although a lot of studies based on Fenton, Struvite, and Electrooxidation techniques were reported in the literature, limited studies were carried out on sequential treatment processes. This study is mainly focused on the enhanced treatment of landfill leachate by sequential processes to overcome the limitation of individual techniques.

\section{Materials and Methodology}

All the laboratory experiments were carried out in a $500 \mathrm{ml}$ batch reactor with a working volume of $250 \mathrm{ml}$. All the experiments were conducted in triplicate and their mean values are represented.

\subsection{Initial characterization of Landfill Leachate}

Landfill leachate was collected from a local landfill site located in Hyderabad. The initial characterization of landfill leachate was done in triplicates and is presented in Table 1.

\subsection{Fenton process}

Fenton process was optimized for reaction time and $\mathrm{H}_{2} \mathrm{O}_{2}$ dosage and experiments were performed. The calculated dosages of $\mathrm{H}_{2} \mathrm{O}_{2}$ and $\mathrm{Fe}^{+2}\left(\mathrm{FeSO}_{4} .7 \mathrm{H}_{2} \mathrm{O}\right)$ were added based on the initial concentration of COD of landfill leachate at $100 \mathrm{rpm}$ [8]. The ratio of constant $\mathrm{Fe}^{+2}$ varying $\mathrm{H}_{2} \mathrm{O}_{2}$ from 5 to 100 with the optimized reaction time (Fig. 1a). Samples were drawn at an interval of $30 \mathrm{~min}$ for $240 \mathrm{~min}$ and analyzed for COD and ammonia.

\subsection{Struvite process}

The struvite process has been optimized for reaction time and $\mathrm{pH}$ with salts $\mathrm{MgCl}_{2} \cdot 6 \mathrm{H}_{2} \mathrm{Oand}$ $\mathrm{Na}_{2} \mathrm{HPO}_{4} .12 \mathrm{H}_{2} \mathrm{O}$ at $100 \mathrm{rpm}$. The dosages of the salts were calculated based on stoichiometric calculations and initial concentration of ammonia and were fixed for molar ratio $\mathrm{Mg}^{+2}: \mathrm{PO}_{4}{ }^{3-}$ 
$: \mathrm{NH}^{4+}$ as $1: 1: 1$. Samples were drawn at an interval of $10 \mathrm{~min}$ for $60 \mathrm{~min}$ and were analyzed for ammonia. With the optimized conditions, ammonia was analyzed for Magnesium salt $\mathrm{MgO}$ (Fig. 1b).

\subsection{Electrooxidation process}

Electrooxidation studies were performed for optimization of reaction time, applied voltage, and inner Electrode distance. The Electrode material used was Stainless steel with of dimensions $100 \mathrm{~mm} \times 50 \mathrm{~mm} \times 2 \mathrm{~mm}$ with a reactive surface area of $40 \mathrm{~cm}^{2}$. The setup was connected to a DC power supply and $\mathrm{pH}$ was maintained at $\mathrm{pH}$ 7. The effect of the applied voltage was studied at $5 \mathrm{~V}$ to $9 \mathrm{~V}$, inner Electrode distance at $1 \mathrm{~cm}, 1.5 \mathrm{~cm}$, and $2 \mathrm{~cm}$ with the optimized reaction time (Fig. 1c) [9].

\subsection{Sequential treatment process}

To enhance the COD and ammonia removal, the sequential processes have been performed with the above optimized operating conditions. The removal efficiency of COD and ammonia were evaluated in two Sequential processes given below (Fig. 2):

1. Sequence-I Fenton followed by Electrooxidation and Struvite

2. Sequence-II Fenton followed by Struvite

\subsection{Analytical methods}

The $\mathrm{pH}$ of the leachate was adjusted with $5 \mathrm{~N} \mathrm{H}_{2} \mathrm{SO}_{4} / 5 \mathrm{~N} \mathrm{NaOH}$ using a $\mathrm{pH}$ meter (FE20, Mettle Toledo, Switzerland). The COD (MN, Hach, Germany) was estimated by digestion method and Ammonia was estimated using Kjeldahl (Pelicon) titrimetric as per standard methods from APHA [10-11]. The samples drawn were filtered by Whatman filter paper No 45 prior to analysis for COD and ammonia. The percentage removal was calculated using the following Eq. (7) [12].

$$
\text { Removal } \%=\frac{\text { Initial Concentration-Final Concentration }}{\text { Initial Concentration }} * 100
$$

\subsection{Operational Cost (OC) analysis}


Economical aspect is a major parameter for assessing the performance of the treatment. The economic aspects for assessing the leachate treatment. The treatment process applied should be preferred based on both efficiency and operating cost. The treatment cost of Fenton, Electrooxidation and Struvite are given by following equations:

$$
\text { Fenton, Struvite } O C=\frac{M * P}{\left[V *\left(C_{\mathrm{i}}-C_{\mathrm{t}}\right)\right]}
$$

Where, $\mathrm{OC}$ is the operating cost, $\mathrm{M}$ is the amount of the chemical consumed $\left(\mathrm{H}_{2} \mathrm{O}_{2}\right.$ in Liters and $\mathrm{FeSO}_{4} . \mathrm{H}_{2} \mathrm{O}$ in $\mathrm{Kg}$ ), $\mathrm{P}$ is the commercial market price of each chemical in $\$, \mathrm{~V}$ is the

\subsection{Fenton process}


Reaction time is an important operational parameter and plays a significant role in degrading organic matter due to the reaction occurring between the $\left[{ }^{\circ} \mathrm{OH}\right]$ and ferrous ions. Hence, in the present study, the effect of the Fenton process was carried out from 30 min to 240 min with constant $\mathrm{pH}$. The influence of [ $\left.{ }^{\circ} \mathrm{OH}\right]$ liberated from $\mathrm{H}_{2} \mathrm{O}_{2}$ may mineralize organic matter which can be correlated with COD. Reduction of COD and ammonia were found linearly increasing with reaction time. It has been evident from Fig. 3a that the maximum removal of COD and ammonia were $75 \%$ and $23 \%$ at $210 \mathrm{~min}$. As per Eqs. (1) and (2), with enough reaction time, the $\left[{ }^{\circ} \mathrm{OH}\right]$ degrade a wide range of organic matter. Further degradation of organic matter decelerated down due to complete consumption of $\left[{ }^{\circ} \mathrm{OH}\right]$. Additionally, some inorganic ions 
$\mathrm{H}_{2} \mathrm{O}_{2}: \mathrm{FeSO}_{4} .7 \mathrm{H}_{2} \mathrm{O}$ and obtained a maximum reduction of COD $75 \%$ with a ratio of 15 using industrial wastewater. In the present study, maximum COD removal efficiency of $75 \%$ was observed with landfill leachate with an initial COD concentration of $24,000 \mathrm{mgL}^{-1}$ with $\mathrm{H}_{2} \mathrm{O}_{2}: \mathrm{FeSO}_{4} .7 \mathrm{H}_{2} \mathrm{O}$ dosage a ratio of 5 .

\subsection{Struvite process}

The Struvite process is effective in the removal of ammonia by chemical precipitation on the addition of Magnesium and phosphorous salts with an equal molar ratio. Appropriate reaction time enhances the reaction between Magnesium, Phosphorous salts, and ammonia for proper formation thereby increasing the settleability of Struvite. The dosages of $\mathrm{MgCl}_{2} \cdot 6 \mathrm{H}_{2} \mathrm{O}$ and $\mathrm{Na}_{2} \mathrm{HPO}_{4} .12 \mathrm{H}_{2} \mathrm{O}$ were added as per the initial concentration of ammonia with the equal molar ratio of $\mathrm{Mg}^{+2}: \mathrm{PO}_{4}{ }^{3-}: \mathrm{NH}^{4+}(1: 1: 1)$ as given in Eq. 6. Experimental observations depict a direct and linear influence of reaction time on Struvite precipitation as shown in Fig. 4a. The maximum Struvite precipitation of $77 \%$ was observed at a reaction time $60 \mathrm{~min}$. Although the maximum removal was attained at $60 \mathrm{~min}$, a significant change in removal was observed at 40 min, therefore, struvite can be operated for $40 \mathrm{~min}$. Based on the observations further increase in the reaction may result in redissolution of precipitated struvite and also affect settleability of Struvite [19]. The presence of competitive ions like $\mathrm{Ca}^{2+}, \mathrm{Na}^{+}, \mathrm{K}^{+}, \mathrm{CO}_{3}{ }^{2-}$, and $\mathrm{HCO}_{3}{ }^{-}$in landfill leachate may interfere in the crystal formation and have a negative effect on the treatment process. The formation of sodium and calcium salts along with Struvite also reduces the ammonia in landfill leachate [20]. Studies by Musa et al., observed ammonia precipitation of $85 \%$ with a dosage of $1.5: 1.5: 1$ with a reaction time of 90 min with calcium pre-treatment $[22]$.

In the Struvite process, $\mathrm{pH}$ plays also a vital role in the ammonia precipitation as Struvite at alkaline conditions. The $\mathrm{pH}$ also affects the balance of ions in crystallization, 
therefore the $\mathrm{pH}$ at the induction time linearly influences the reaction and equilibrium in the system. The effect of $\mathrm{pH}$ has been investigated from 3-11 at a variation of 2. At $\mathrm{pH} 9,74 \%$ of efficiency was observed in Struvite precipitation as represented in Fig. 4b. The solubility of struvite is minimum at a higher $\mathrm{pH}$ range from 7 to 9 , so $\mathrm{pH}$ in the mentioned range is used in the Struvite process. Above $\mathrm{pH} \mathrm{9,} \mathrm{Struvite} \mathrm{solubility} \mathrm{increases} \mathrm{which} \mathrm{leads} \mathrm{to} \mathrm{a} \mathrm{decrease} \mathrm{in}$ ammonia concentration [21]. Similar findings were reported by Wang et al., who stated that $\mathrm{pH} 9$ is appropriate for the Struvite process and above $\mathrm{pH} 9$ solubility of struvite increases [22].

The effect of ammonia reduction by replacing $\mathrm{MgCl}_{2} \cdot 6 \mathrm{H}_{2} \mathrm{O}$ with $\mathrm{MgO}$ has been investigated at the above-optimized reaction time and $\mathrm{pH}$ of $40 \mathrm{~min}$ and 9.0 respectively. Additionally, using $\mathrm{MgCl}_{2} .6 \mathrm{H}_{2} \mathrm{O}$ in Struvite precipitation may have some interferences with chlorides, carbonates, and bicarbonates present in it, so the Struvite process with $\mathrm{MgO}$ was investigated. From the experimental study, it was observed that both the Magnesium salts have a significant effect in reducing ammonia in landfill leachate by $74 \%$ and $58.33 \%$ respectively as shown in Fig. 4c. Despite the interferences caused by using $\mathrm{MgCl}_{2} \cdot 6 \mathrm{H}_{2} \mathrm{O}$, higher efficiency has been observed when compared to $\mathrm{MgO}$. The dissolution of $\mathrm{MgO}$ in aqueous solutions is minimal and forms intermediates like $\mathrm{Mg}(\mathrm{OH})_{2}$ which further increases the $\mathrm{pH}$ of landfill leachate. This increase in $\mathrm{pH}$ may have a negative effect on crystal formation [23].

\subsection{Electrooxidation process}

In Electrooxidation, reaction time was investigated at a time interval of $10 \mathrm{~min}$ for $60 \mathrm{~min}$. Fig. 5(a) depicts the effect of COD and ammonia removal with reaction time. The maxim um of COD and ammonia reduction was found to be $58.25 \%$ and $44 \%$ respectively at a 60 min reaction time. On further increase in the reaction time, no significant increase in the removal of COD and ammonia was observed. After $60 \mathrm{~min}$, the formation of a passive layer on the electrodes may have occurred which reduces the effectiveness of electrooxidation [24-25]. 
Similar studies were also conducted by Mussa et al [26] who observed maximum COD removal of $39 \%$ at 105 min with $5 \mathrm{~V}$.

The applied voltage directly influences the performance of Electrooxidation for landfill leachate. The experiment was carried out with different voltages range between $5 \mathrm{~V}$ and $9 \mathrm{~V}$ at a reaction time of $60 \mathrm{~min}$ and current $2.5 \mathrm{~A}$ and its effect were investigated. It has been observed that with an increase in applied voltage, reduction in COD and ammonia also increased. The maximum reduction of COD and ammonia were found to be $58.25 \%$ and $44 \%$ respectively at $8 \mathrm{~V}$ as shown in Fig. 5b. The applied voltage is the potential difference that may lead to the formation of certain reactive species like hydroxyl radicals. The gradual increase in applied voltage leads to an increase in the generation of hydroxyl radicals, thereby enhancing the degradation of organic matter [26]. Similar results were reported by Li et al [6] and stated that further increase in applied voltage above $8 \mathrm{~V}$ slows down the removal of COD and ammonia.

The inner Electrode distance and its role in degrading the organic matter by Electrooxidation were investigated. Inner Electrode distance of anode and cathode was varied in the range $1,1.5$, and $2 \mathrm{~cm}$. Fig. $5 \mathrm{c}$ illustrates that a decrease in COD and ammonia were observed with an increase in inner electrode distance. The removal efficiency may have increased due to faster discharge of anions at the anode and accelerated oxidation [28].

\subsection{Sequential treatment process}

Due to the diversified characteristics of landfill leachate, individual treatment processes may not be effective in treating COD and ammonia. To overcome this problem two Sequential treatments were examined:

1. Sequence-I includes Fenton followed by Electrooxidation and Struvite

2. Sequence-II includes Fenton followed by Struvite. 

out from the above-optimized conditions. From Figure 6, in the Sequence-I (Fenton followed by Electrooxidation and Struvite) the removal of COD and ammonia were $89 \%$ and $82 \%$ respectively. In Sequence-II (Fenton followed by Struvite) the removal of COD and ammonia were $76.67 \%$ and $77 \%$ respectively. The Electrooxidation followed by Struvite further enhances the removal of COD and ammonia after the Fenton process.

\subsection{Cost Estimation}

The overall cost for estimation for the treatment processes have been given in the Table 2 which are calculated by Eqs. (8) (9) (10) and (11). The cost evaluated for maximum COD and ammonia removal at the optimized operating parameters. The operational cost was maximum for the Electrooxidation as for its energy consumption while Fenton and Struvite has less operational cost individually. Both the sequential process has shown maximum COD and ammonia removal and their respective operational costs are 7.5 and $0.12 \$ \mathrm{~m}^{-3}$. Sequence-I has high cost as it includes the Electrooxidation process. Very few studies are reported in the literature regarding the determination of operating cost for Sequential treatment of landfill leachate treatment. Guvence and Varank [13] have reported the individual Fenton cost as 0.238 $€ \mathrm{~g}^{-1}$ COD removed. Cortez [29] has determined the operating cost of leachate treatment by the

278 Fenton process as $8.2 € \mathrm{~m}^{-3} \mathrm{~g}^{-1}$ of COD removed. Bhagawan et al [27] has determined the step

279 by step cost evaluation for the Electro-coagulation process. Hence it can be concluded that Sequential treatment of landfill leachate operational cost by optimizing the operational than the individual processes.

\section{Conclusions}


The present study aims towards the enhancement of COD and ammonia reduction in the landfill leachate by Fenton, Electrooxidation and Struvite techniques in individual and sequence treatment process. The results showed that all the individual process were considerable in the reduction of COD and ammonia at the respective optimized conditions. The sequential treatment process were found to be more effective than the individual treatment process since they overcome the limitations of individual process. The maximum reduction of COD and ammonia were $89 \%$ and $82 \%$ in Sequence-I and $82 \% ; 76.67 \%$ in Sequence-II. It can be concluded that Sequence-I process (Fenton followed by Electrooxidation and Struvite) is feasible for COD and ammonia reduction in the landfill leachate. Further studies would be conducted for the effect of Sequence-I treatment process in pilot scale.

\section{Declarations:}

Availability of data and material: All the related to this manuscript was included in the manuscript.

Conflict of interests: All authors have seen and approved the manuscript being submitted. Hence, on behalf of all authors, the corresponding author states that there is no conflict of interest.

Funding: The research leading to these results received funding from the Department of Science and Technology (DST), Ministry of Science and Technology, Government of India/Bharat Sarkar, under Grant Agreement DST/TDT/WM/2019//27(G).

One of the authors Dr. D Bhagawan received research support from the University Grants Commission (UGC), Government of India/Bharat Sarkar with Grant Order no. F./311/2017/PDFSS-2017-18-TEL- 14164.

Code availability: Not applicable.

Authors' contributions: Vurimindi Himabindu- conceptualization, methodology and review, Srinath Suranani -conceptualization, project administration, Sushma Lavudya - 
conceptualization, methodology, writing original draft, Maneesha Vodnala - methodology, writing original draft, Kirankumar Panga - review and editing draft, Saranga Vijaya Krishna review and editing draft, Bhagawan Dheeravath - methodology, review final draft Shankaraiah

312 Golla - review and editing draft.

313 Acknowledgements: The research leading to these results received funding from the 314 Department of Science and Technology (DST), Ministry of Science and Technology, 315 Government of India/Bharat Sarkar, under Grant Agreement DST/TDT/WM/2019//27(G).

316 One of the authors Dr. D Bhagawan received research support from the University Grants 317 Commission (UGC), Government of India/Bharat Sarkar with Grant Order no. F./311/2017/PDFSS-2017-18-TEL- 14164.

\section{References}

1. Jaafarzadeh Haghighifard NA, Jorfi S, Ahmadi M, Mirali S, Kujlu R. Treatment of mature landfill leachate by chemical precipitation and Fenton advanced oxidation process. Environmental Health Engineering and Management Journal. Winter. 2016 ;3(1):35-40.

2. Reshadi MAM, Bazargan A, McKay G. A review of the application of adsorbents for landfill leachate treatment: Focus on magnetic adsorption. Science of The Total Environment. 2020;138863.

3. Zhang MH, Dong H, Zhao L, Wang DX and Meng D. A review on Fenton process for organic wastewater treatment based on optimization perspective. Science of the total environment. 2019;11(9);670:110-121.

4. Sruthi T, Gandhimathi R, Ramesh ST, Nidheesh PV. Stabilized landfill leachate treatment using heterogeneous Fenton and electro-Fenton processes. Chemosphere. 2018:38-43. 
5. Bashir Mohammed, Lim Jun-Wei Aziz, Shuokr Qarani, Abu Amr, Salem. Electrochemical Oxidation Process Contribution in Remediating Complicated Wastewaters. 2014;7(5): 103352.

6. Li Z, Ren X, Zuo J, Liu Y, Duan E, Yang J, Chen P, Wang Y. Struvite precipitation for ammonia nitrogen removal in 7-aminocephalosporanic acid wastewater. Molecules. $2012 ; 17(2): 2126-2139$.

7. Maharaja P, Gokul E, Prabhakaran N, Karthikeyan, S, Boopathy R, Swarnalatha S, Sekaran, G. Simultaneous removal of NH 4+-N and refractory organics through sequential heterogeneous Fenton oxidation process and struvite precipitation: kinetic study. RSC advances. 2016;6(5): 4250-4261.

8. Tiwari AK. and Upadhyay VK. Fenton's reagent dose calculation with respect to COD value and the process requirement optimization for effective oxidation of Aqueous Mother Liquor Effluent of an API manufacturing industry at large scale. International journal of advanced research. 2013: 158-164.

9. Krishna SV, Kumar PK, Verma K, Bhagawan D, Himabindu V, Narasu ML, Singh R. Enhancement of biohydrogen production from distillery spent wash effluent using electrocoagulation process. Energy, Ecology and Environment. 2019;4(4):160-165.

10. American public health association. Standard methods for the examination of water and wastewater.2005.

11. Saranga VK, Kumar PK, Verma K, Bhagawan, D, Himabindu V, Narasu ML. Effect of biohythane production from distillery spent wash with addition of landfill leachate and sewage wastewater. Applied biochemistry and biotechnology. 2020;190(1):30-43.

12. Kumar PK, Krishna SV, Verma K, Pooja K, Bhagawan D, Himabindu V. Phycoremediation of sewage wastewater and industrial flue gases for biomass generation from microalgae. South African journal of chemical engineering. 2018; 25:133-146. 
13. Guvenc SY, Varank G. Degradation of refractory organics in concentrated leachate by the Fenton process: Central composite design for process optimization. Frontiers of Environmental Science \& Engineering. 2021:1-16.

14. Bhagawan D, Poodari S, Pothuraju T, Srinivasulu D, Shankaraiah G, Rani MY, Himabindu V, Vidyavathi S. Effect of operational parameters on heavy metal removal by electrocoagulation. Environmental Science and Pollution Research. 2014;21(24):1416614173.

15. Pani, N, Tejani V, Anantha-Singh TS Kandya A. Simultaneous removal of COD and Ammoniacal Nitrogen from dye intermediate manufacturing Industrial Wastewater using Fenton oxidation method. Applied Water Science. 2020; 10(2):1-7.

16. Pereira CAM, Brito NN. Integration of treatment technologies with Fenton reagent for laboratory effluent remediation. Revista Ambiente \& Água.2018:13(5).

17. Tony MA, Bedri Z. Experimental design of photo-Fenton reactions for the treatment of car wash wastewater effluents by response surface methodological analysis. Advances in Environmental Chemistry.2014.

18. Deng Y, Zhao R. Advanced oxidation processes (AOPs) in wastewater treatment. Current Pollution Reports. 2015;1(3):167-176.

19. Siciliano A, Limonti C., Curcio GM, Molinari R. Advances in Struvite Precipitation Technologies for Nutrients Removal and Recovery from Aqueous Waste and Wastewater. Sustainability. 2020;12(18):7538.

20. Rahaman M S, Ellis N, Mavinic D S. Effects of various process parameters on Struvite precipitation kinetics and subsequent determination of rate constants. Water Science and Technology.2008;57(5):647-654. 
21. Tonetti AL, de Camargo CC, Guimarães JR. Ammonia removal from landfill leachate by struvite formation: an alarming concentration of phosphorus in the treated effluent. Water Science and Technology.2016;74(12):2970-2977.

22. Wang H, Tian Z, Wang H, Yan Q. Optimization and reaction kinetics analysis for phosphorus removal in struvite precipitation process. Water Environment Research.2020;92(8):1162-1172.

23. Stolzenburg P, Capdevielle A, Teychené S, Biscans B. Struvite precipitation with MgO as a precursor: Application to wastewater treatment. Chemical Engineering Science.2015;133:9-15.

24. Bhagawan D, Poodari S, Chaitanya N, Ravi S, Rani YM, Himabindu V, Vidyavathi S. Industrial solid waste landfill leachate treatment using electrocoagulation and biological methods. Desalin. Water Treat. 2017;68:137-142.

25. Sirés I, Brillas E, Oturan MA, Rodrigo MA, Panizza M. Electrochemical advanced oxidation processes: today and tomorrow. A review. Environmental Science and Pollution Research. 2014:8336-8367.

26. Mussa ZH, Othman MR, Abdullah MP. Electrochemical oxidation of landfill leachate: investigation of operational parameters and kinetics using graphite-PVC composite electrode as anode. Journal of the Brazilian Chemical Society. 2015;26(5):939-948.

27. Bhagawan D, Poodari S, Pothuraju T, Srinivasulu D. Shankaraiah,G. Rani,MY, Himabindu V, Vidyavathi S. Effect of operational parameters on heavy metal removal by electrocoagulation. Environmental Science and Pollution Research. 2014;21(24):1416614173.

28. Bashir MJ, Aziz HA, Aziz SQ, Abu Amr SS. An overview of electro-oxidation processes performance in stabilized landfill leachate treatment. Desalination and water treatment. 2013;51(10-12):2170-2184. 
409

410

411

412

413

414

415

416

417

418

419

420

421

422

423

424

425
29. Cortez S, Teixeira P, Oliveira R, Mota M. Evaluation of Fenton and ozone-based advanced oxidation processes as mature landfill leachate pre-treatments. Journal of environmental management. 2011:749-755. 

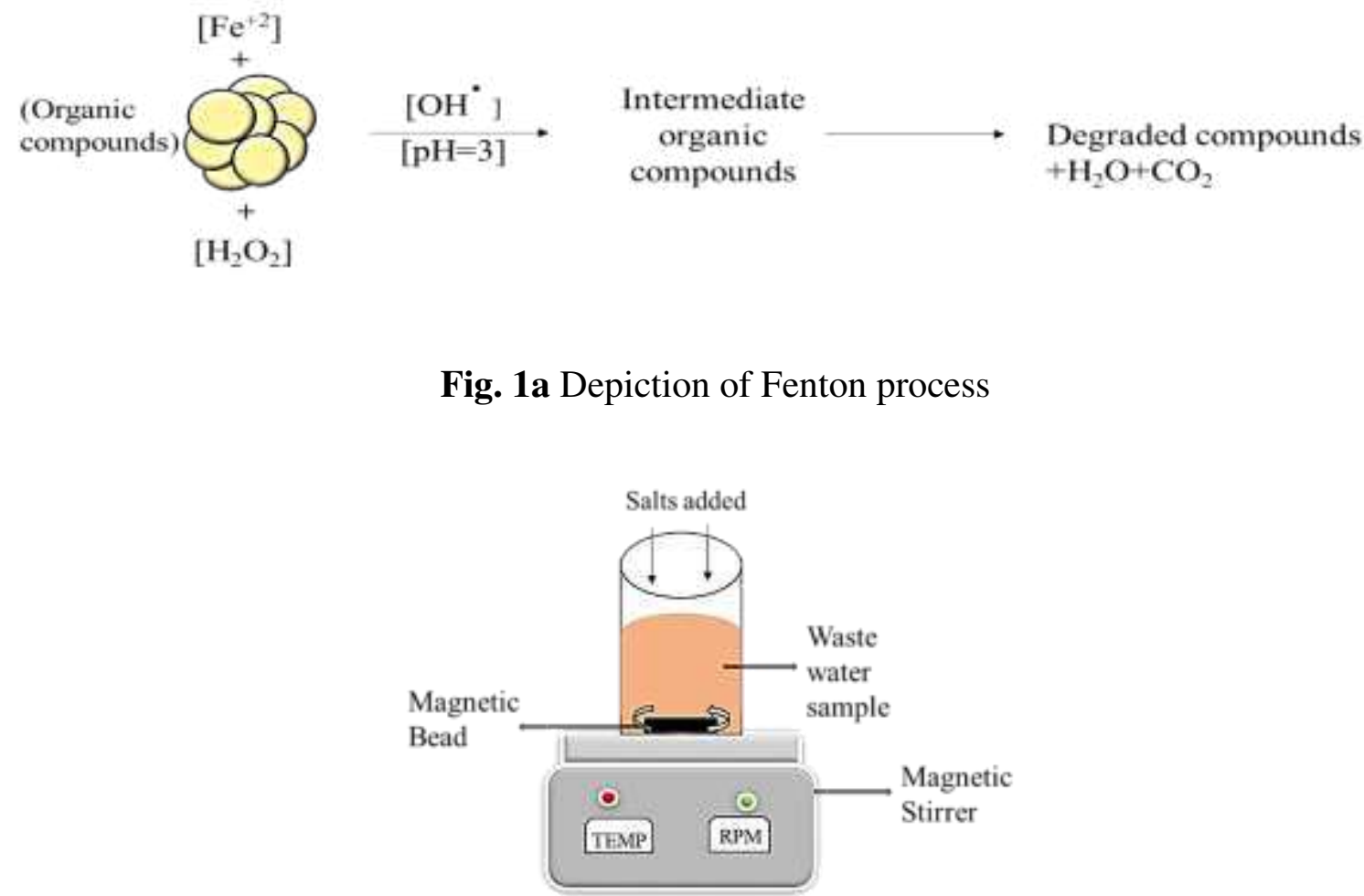

Fig. 1b Schematic representation of laboratory Struvite Precipitation setup

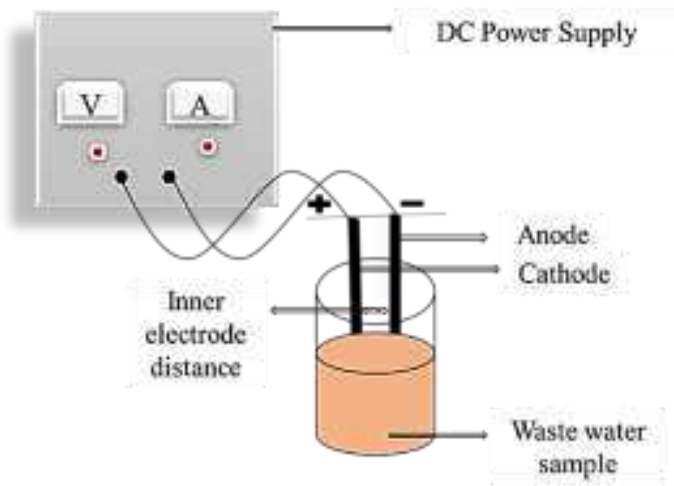

Fig. 1c Schematic representation of laboratory Electro-oxidation setup 


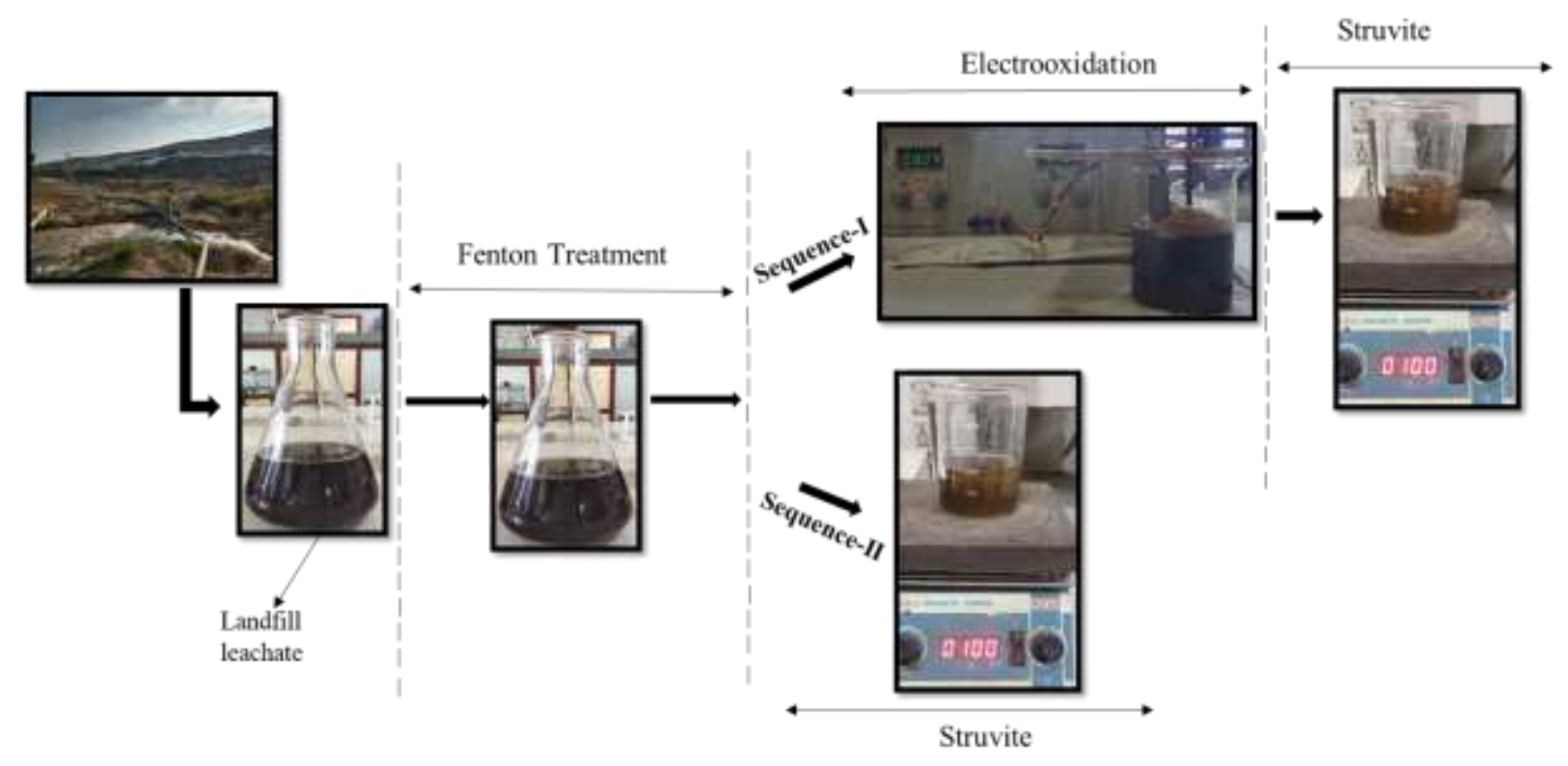

Fig. 2 Process flow diagram of Sequential treatment

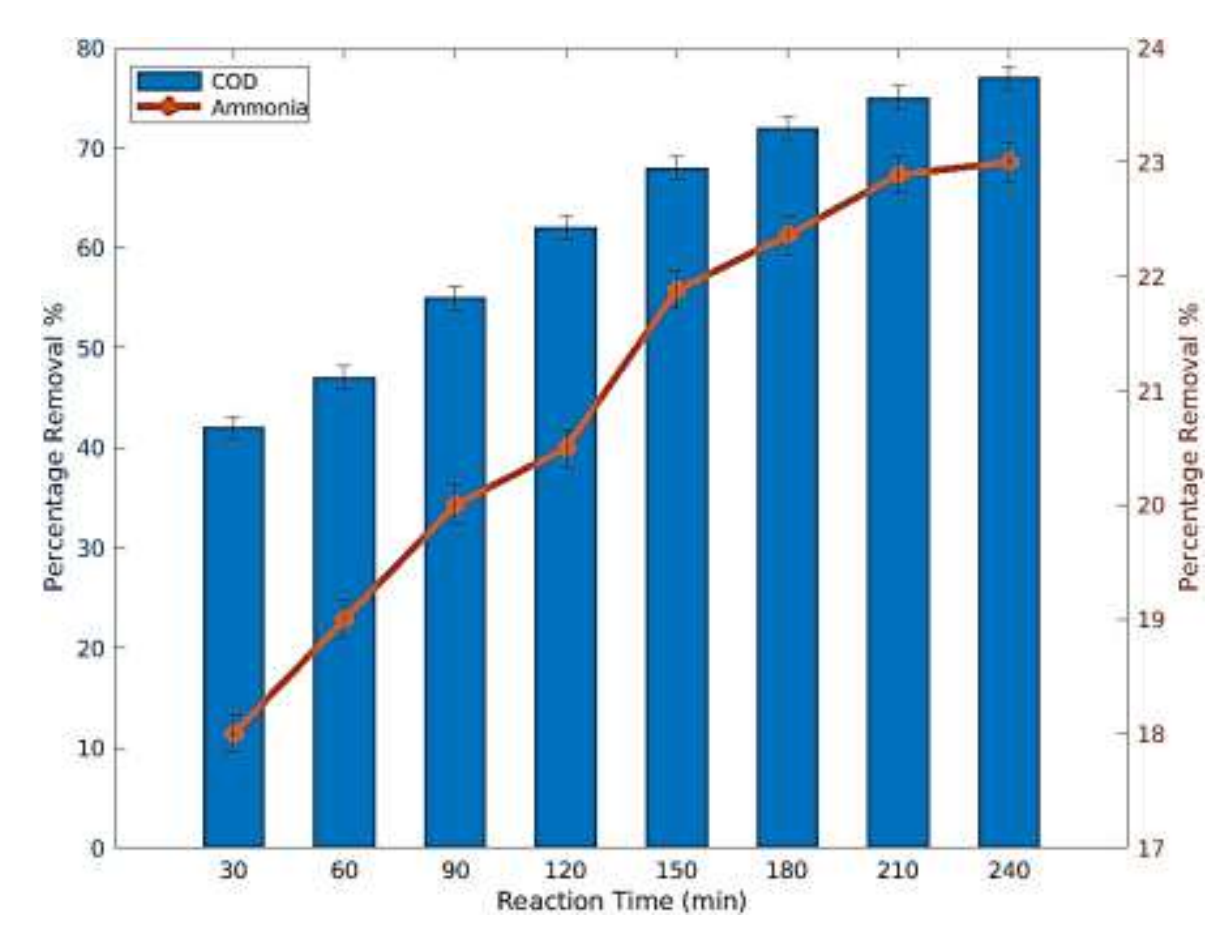

Fig. 3a Effect of reaction time on the removal of COD and ammonia in Fenton process 


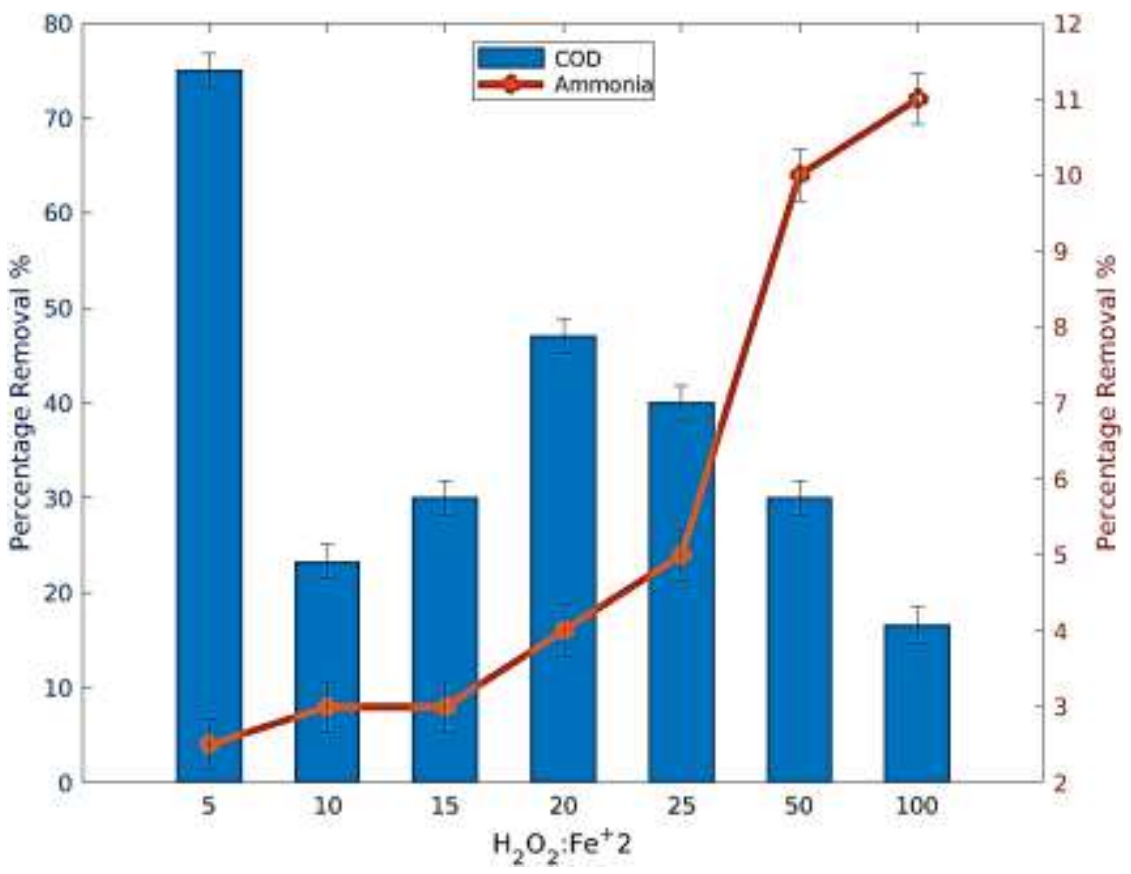

Fig. 3b Effect of $\mathrm{H}_{2} \mathrm{O}_{2}$ dosage on removal of COD and ammonia in Fenton process

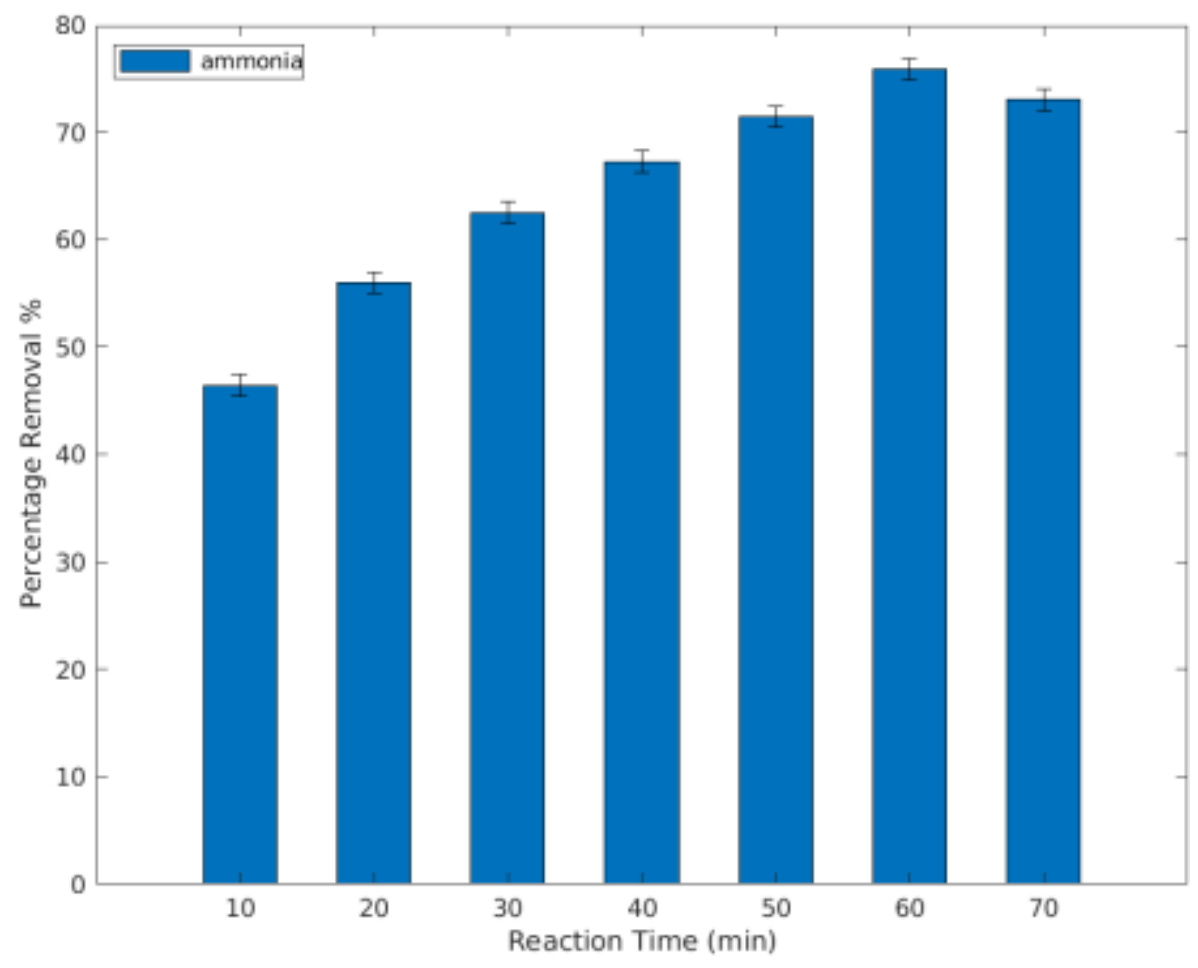

Fig. 4a Effect of reaction time on ammonia in Struvite precipitation 


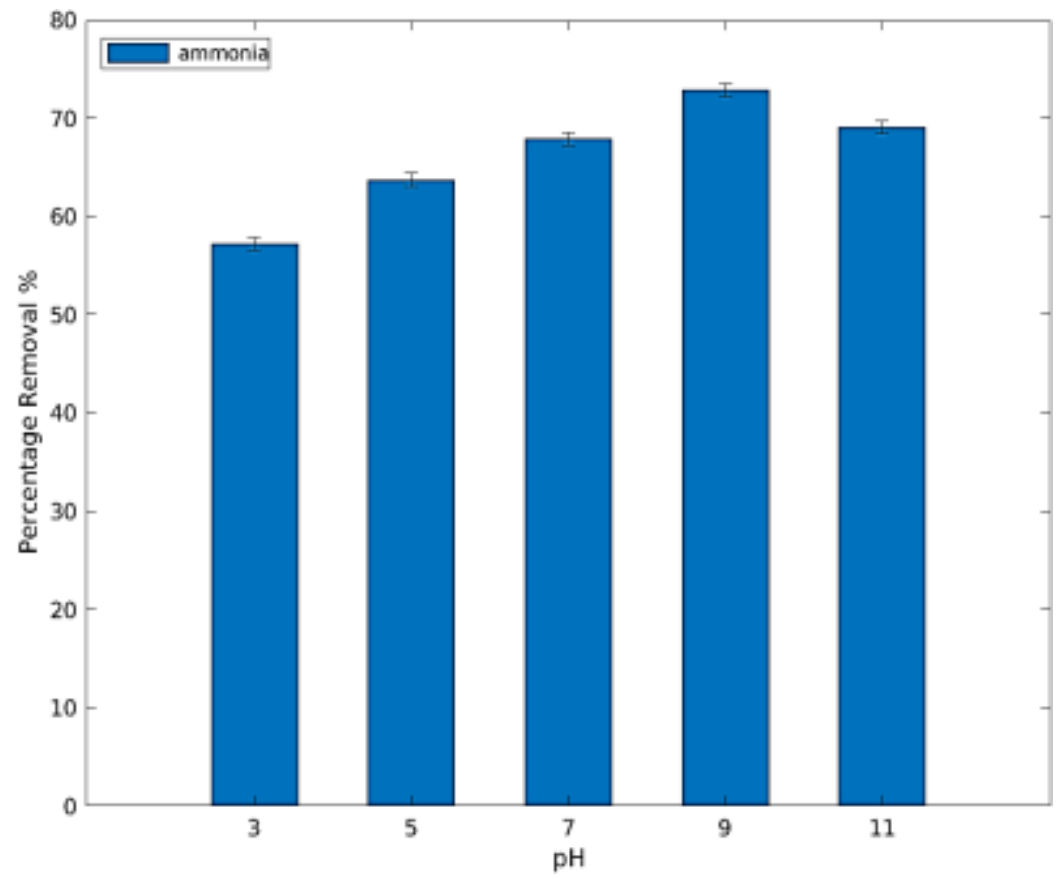

442

Fig. 4b Effect of $\mathrm{pH}$ on ammonia in Struvite precipitation

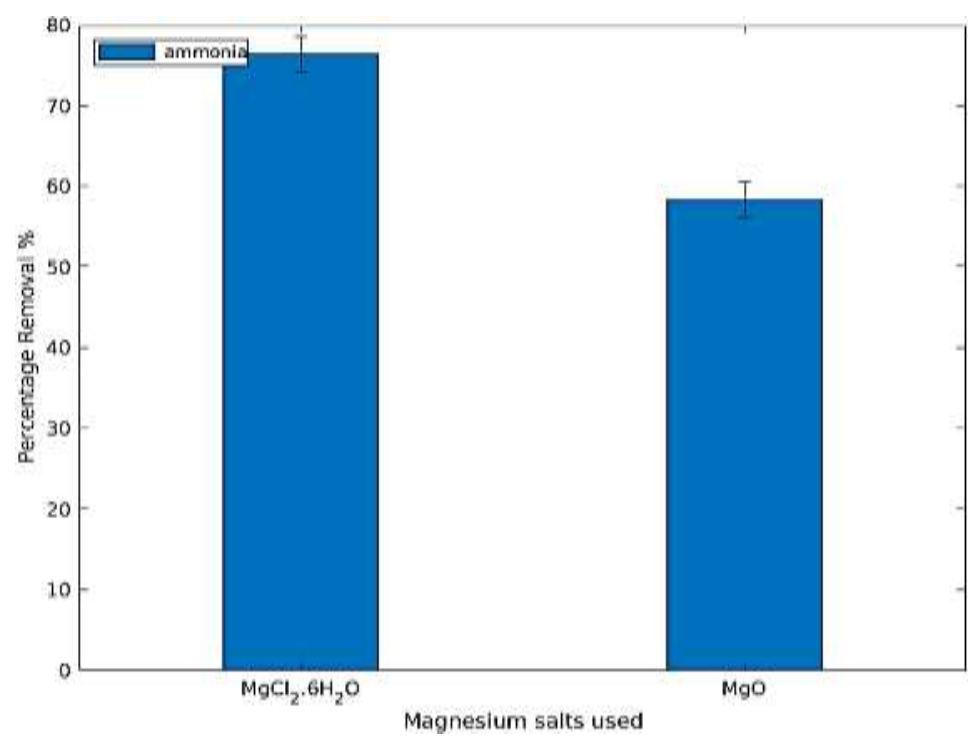

Fig. 4b Comparison of the effect of $\mathrm{MgCl}_{2} \cdot 6 \mathrm{H}_{2} \mathrm{O}$ and $\mathrm{MgO}$ on ammonia in Struvite process 


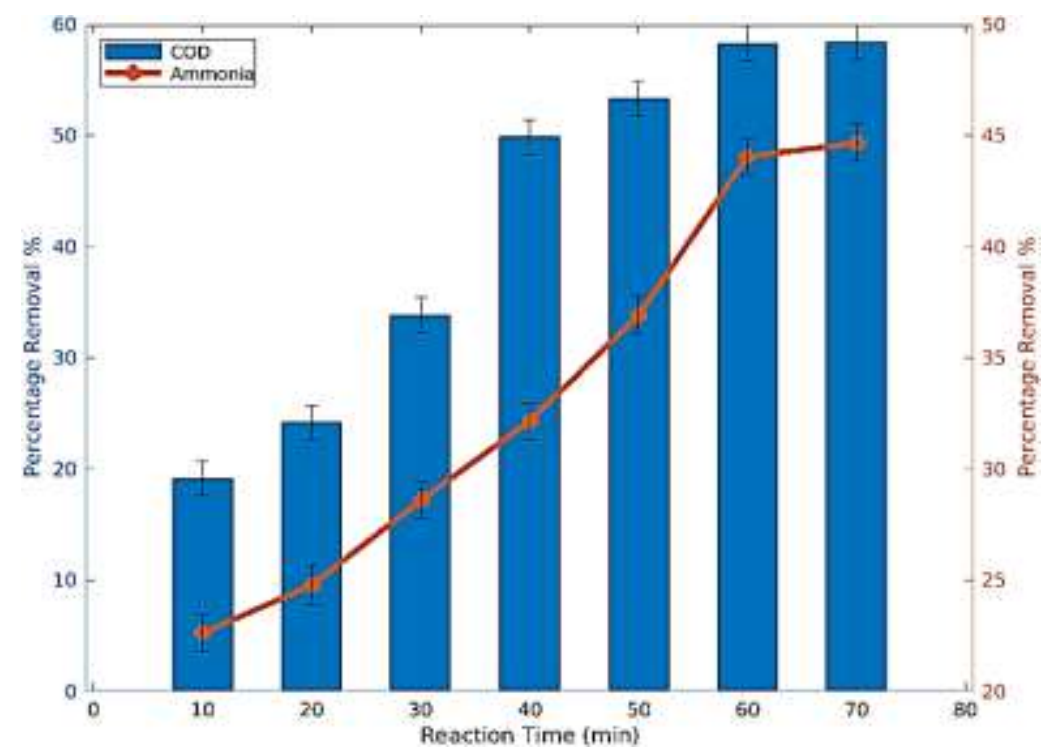

Fig. 5a Effect of reaction time COD and ammonia by Electrooxidation

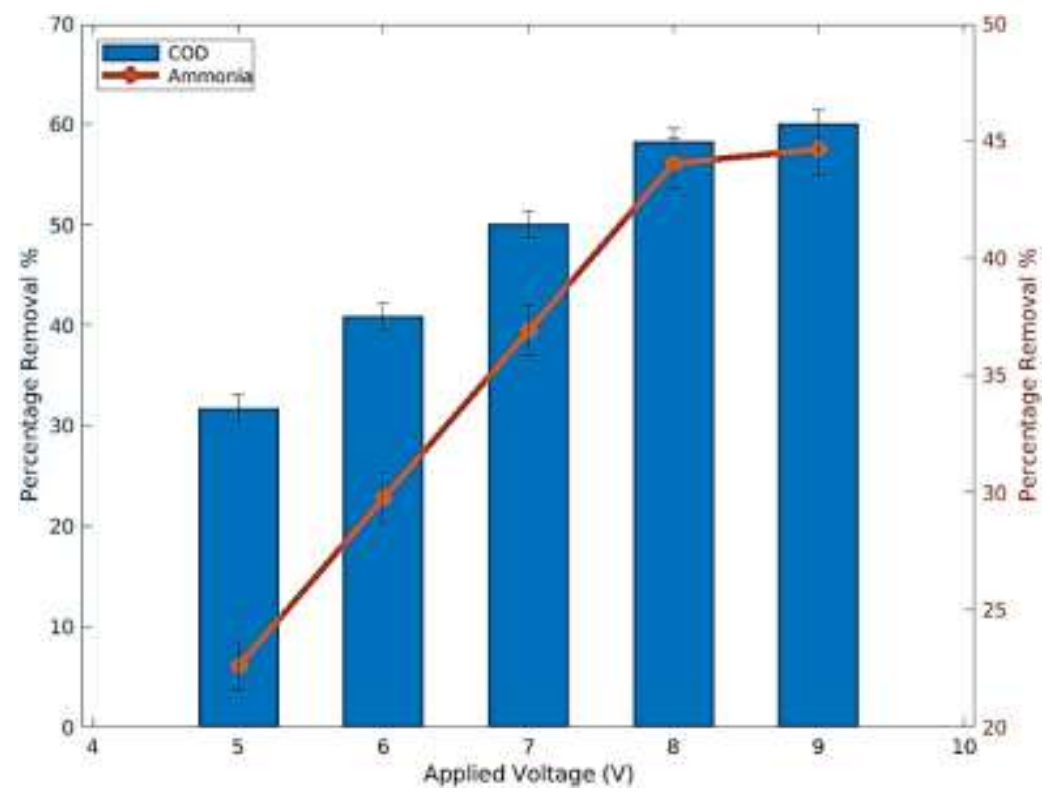

Fig. 5b Effect of Applied voltage 


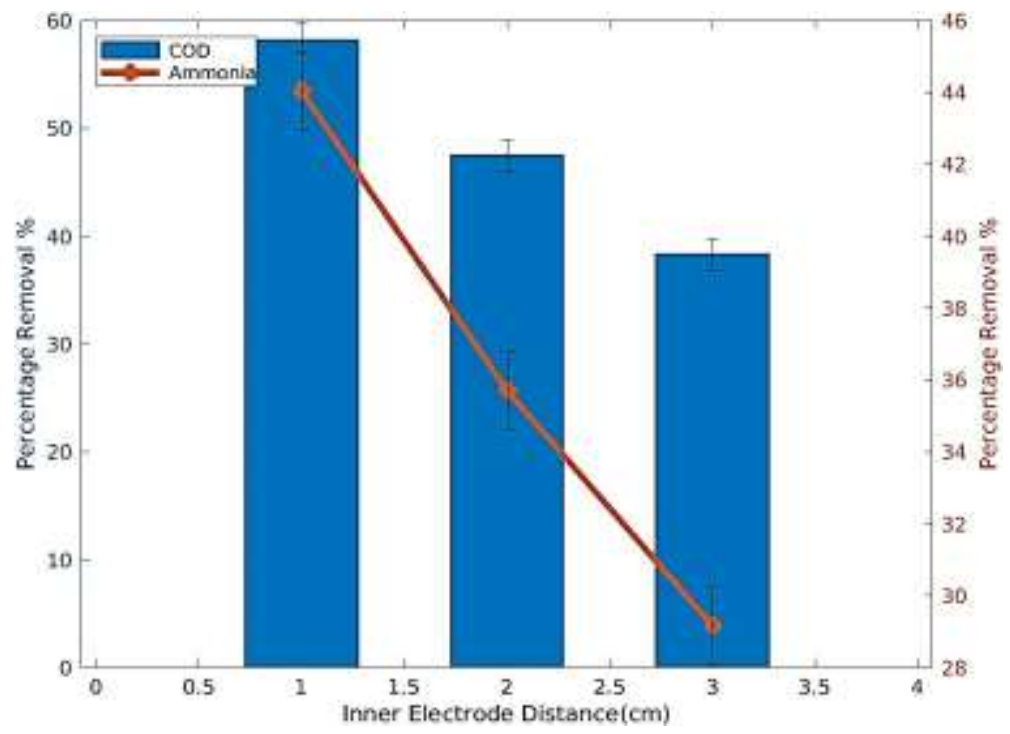

Fig. 5c Effect of Inner Electrode distance

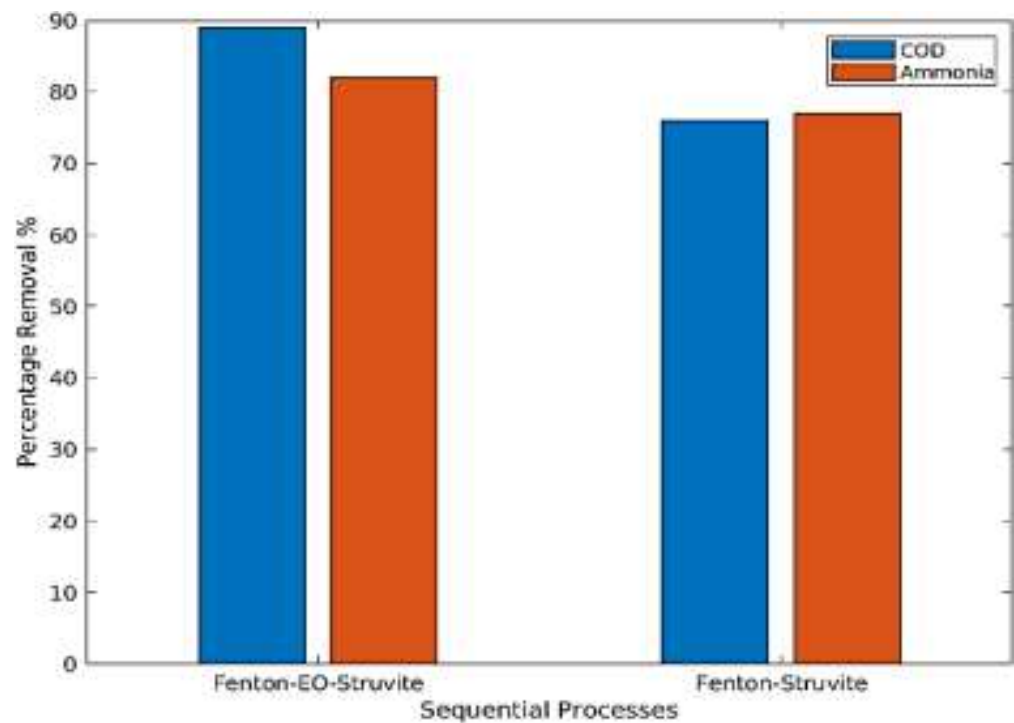

Fig. 6 COD and ammonia removal \% in Sequence-I and Sequence-II

Table 1 Initial Characterization of landfill leachate

\section{S. No.}

Parameters

Concentration \pm S. D

\begin{tabular}{ccc}
\hline 1 & $\mathrm{pH}$ & $8.58 \pm 0.5$ \\
\hline 2 & Electrical conductivity $(\mathrm{mS})$ & $40.6 \pm 0.3$ \\
\hline 3 & Chemical Oxygen Demand (COD) $\left(\mathrm{mgL}^{-1}\right)$ & $24,000 \pm 50$
\end{tabular}




\begin{tabular}{lll}
\hline 4 & Chlorides $\left(\mathrm{mgL}^{-1}\right)$ & $8,330 \pm 30$
\end{tabular}

Total Dissolved Solids (TDS) $\left(\mathrm{mgL}^{-1}\right)$

$25,000 \pm 150$

459

Table 2 Cost estimation of the treatment process.

\section{S. No Treatment Process}

\begin{tabular}{ccc}
\hline 1 & Fenton & 0.0214 \\
\hline 2 & Struvite & 0.095 \\
3 & Electrooxidation & 7.38 \\
\hline 4 & Sequence-I & 7.5 \\
\hline 5 & Sequence-II & 0.12
\end{tabular}

Total Cost at optimised parameters $\left(\$ \mathbf{~ m}^{-3}\right)$ 